\title{
IMMUNE RECONSITUTION INFLAMMATORY SYNDROME AMONG ADOLESCENTS: A REPORT OF CASES IN A RESOURCE-LIMITED SETTING (UGANDA)
}

\author{
Christine Katusiime ${ }^{1}, M B C h B, P G D P P M$ \\ Ponsiano Ocama ${ }^{2}, M B C h B$, MMed \\ Andrew Kambugu' ${ }^{1}, M B C h B, M M e d$ \\ ${ }^{1}$ Makerere University, College of Health Sciences, Infectious Diseases Institute, Kampala, Uganda \\ ${ }^{2}$ Makerere University, College of Health Sciences, Department of Medicine, Kampala, Uganda
}

\begin{abstract}
We report immune reconstitution inflammatory syndromes in a cohort of adolescents/young adults over a period of 1 year at the Infectious Diseases Institute, Kampala, Uganda.
\end{abstract}

The immune reconstitution inflammatory syndrome (IRIS) is a frequent early complication of antiretroviral therapy (ART), particularly in patients who commence ART with low CD4 counts and established opportunistic infections. IRIS in HIV-infected patients results from a pathological inflammatory response to pre-existing infective, host or other antigens, alive or dead, causing clinical deterioration after initiating ART. ${ }^{1}$ The most common forms of IRIS occur in association with mycobacterial and herpesvirus infections. ${ }^{2}$

Adolescents and young adults comprise an increasing proportion of new HIV infections both in developing and developed countries, and little is known regarding HIV IRIS in this group. As the ART roll-out has gathered pace since 2004 in resource-limited settings, adolescent IRIS has emerged as a clinical challenge. We describe adolescent/young adult patients who presented to our clinic with IRIS events.

\section{METHODS}

The study was performed at the Adult Infectious Diseases Institute (IDI) at Mulago Hospital, Kampala, Uganda. The AIDC is part of the Makerere University Infectious Diseases Institute and provides HIV care, including free ART, to HIV-infected patients with a CD4+ count $<200$ cells $/ \mu$ l or with World Health Organization stage IV disease. The study was approved by the ethics panel and the Institutional Review Board since this was a case series. Among our adolescent/ young adult cohort aged $16-24$ years of about 480 , we have seen 6 cases of IRIS, including cryptococcal meningitis IRIS, Kaposi's sarcoma IRIS, herpes zoster IRIS, pulmonary tuberculosis IRIS and 2 cases of oral candidiasis IRIS within the past 12 months. The incidence of IRIS after initiation of HAART was 1.25\%. The median age of presentation was 22 years and the median CD4+ count before commencing ART 65 cells/ $\mu$ I. IRIS presented a median of 6 weeks from the start of HAART (range $3-16$ weeks).

Mycobacteria are by far the most common pathogens associated with IRIS in HIV-infected patients..$^{3-7}$ Other infections that have been associated with IRIS events include varicella zoster, herpes simplex, meningeal cryptococcosis, hepatitis, cytomegalovirus retinitis, progressive multifocal leuco-encephalopathy and intestinal parasites. While the majority of IRIS events are infectious in nature, auto-immune IRIS reactions have also been described in adults. ${ }^{8}$

\section{DISCUSSION}

IRIS is a condition seen in some cases of AIDS or immunosuppression, in which the immune system begins to recover but then responds to a previously acquired opportunistic infection with an overwhelming inflammatory response that paradoxically makes the symptoms of infection worse. ${ }^{9}$ It is thought that the immunopathological response initiated by HAART restores the immune response against pathogenic antigens. ${ }^{10}$ There is paradoxical worsening of preexisting infectious processes following initiation of HAART in HIV-infected individuals. ${ }^{9}$

These cases highlight the risks faced during immune reconstitution in adolescent and young adult patients who commence ART with advanced immunosuppression. 
TABLE I. TABLE DISPLAYING AGES, ABSOLUTE CD4 COUNTS AND PRESENTATION TIME OF IRIS AMONG ADOLESCENTS/YOUNG ADULTS OVER 1 YEAR AT THE INFECTIOUS DISEASES INSTITUTE, KAMPALA

\begin{tabular}{|c|c|c|c|}
\hline Age (yrs) & $\begin{array}{l}\text { CD4 counts at initiation of } \\
\text { HAART (cells } / \mu \mathrm{l})\end{array}$ & IRIS condition & $\begin{array}{l}\text { Time from start of HAART } \\
\text { to onset of IRIS (wks) }\end{array}$ \\
\hline 19 & 45 & Pulmonary tuberculosis & 4 \\
\hline 20 & 77 & Oral candidiasis & 6 \\
\hline 21 & 56 & Kaposi's sarcoma & 3 \\
\hline 23 & 65 & Herpes zoster & 9 \\
\hline 24 & 65 & Cryptococcal meningitis & 16 \\
\hline 24 & 73 & Oral candidiasis & 6 \\
\hline
\end{tabular}

\section{CONCLUSION}

IRIS occurs in adolescents and young adults, but little is known about IRIS in general and minimal research has been conducted in the adolescent/young adult age group.

\section{REFERENCES}

1. Lehloenya $R$, Meintjes G. Dermatologic manifestations of the immune reconstitution inflammatory syndrome. Dermatol Clin 2006; 24: 549-570.

2. French MA. Disorders of immune reconstitution in patients with HIV infection responding to antiretroviral therapy. Curr HIV/AIDS Rep 2007; 4: 16-21.

3. Fishman JE, Saraf-Lavi $E$, Narita M, Hollender ES, Ramsinghani R, Ashkin D. Pulmonary tuberculosis in AIDS patients: transient chest radiographic worsening after initiation of antiretroviral therapy. AJR Am J Roentgenol 2000; 174: 43-49.

4. French MA. 'Tuberculosis' after commencing antiretroviral therapy in HIV patients from countries where Mycobacterium tuberculosis infection is common. AIDS 2006; 20: 473-474.

5. John M, French MA. Exacerbation of the inflammatory response to Mycobacterium tuberculosis after antiretroviral therapy. Med J Aust 1998; 169: 473-474.

6. Narita $M$, Ashkin D, Hollender ES, Pitchenik AE. Paradoxical worsening of tuberculosis following antiretroviral therapy in patients with AIDS. Am J Respir Crit Care Med 1998: 158: 157-161.

7. Phillips $\mathrm{P}$, Kwiatkowski MB, Copland M, Craib K, Montaner J. Mycobacterial lymphadenitis associated with the initiation of combination antiretroviral therapy. J Acquir Immune Defic Syndr Hum Retrovirol 1999; 20: 122-128.

8. Viani RM. Sarcoidosis and interstitial nephritis in a child with acquired immunodeficiency syndrome: implications of immune reconstitution syndrome with an indinavir-based regimen. Pediatr Infect Dis J 2002; 21: 435-438.

9. DeSimone JA, Pomerantz RJ, Babinchak TJ. Inflammatory reactions in HIV infected persons after initiation of highly active antiretroviral therapy. Ann Intern Med 2000: 133: 447-454.

10. French $M A$, Price $P$, Stone SF. Immune restoration disease after antiretroviral therapy. AIDS 2004; 18: 1615-1627.

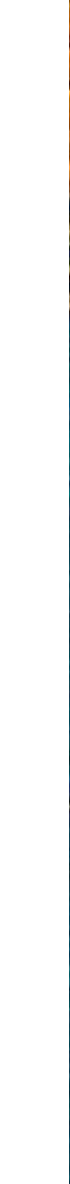

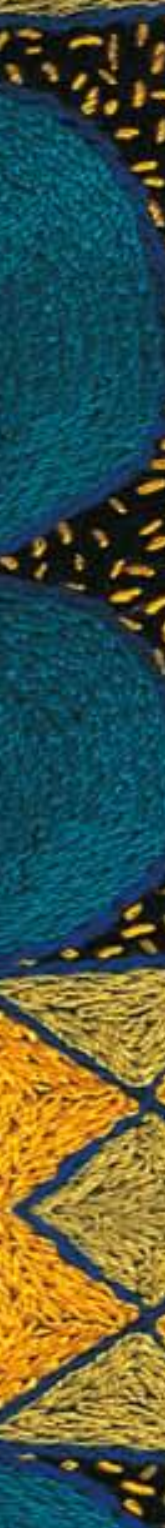

\section{SANBS'S POLICY ON BLOOD DONATIONS FROM MEN WHO HAVE SEX WITH MEN}

To the Editor: We at the South African National Blood Service (SANBS) are acutely aware of the issues surrounding the exclusion of men who have sex with men (MSM) from donating blood and the negative emotions that surround this policy. I would like to assure readers that SANBS does not make such decisions lightly, and we constantly review policies based on the latest scientific findings. It is perhaps time to review the basis of the current policy and engage in debate on its scientific merit.

It is, however, important to clarify a few misconceptions regarding our policies on the sexual activities of our donors.

In an editorial comment on 6 January 2010, the editor of The Herald newspaper in Port Elizabeth stated: 'A pattern of multiple partners or of unprotected sex ... is clearly also high-risk and yet heterosexual donors who may be sexually reckless are spared prying questions and the possible refusal of their offer of blood." This statement is factually incorrect. When donating blood, all donors, whatever their sexual orientation, have to answer very personal questions regarding their sexual activities during the preceding 6 months. ${ }^{2}$

Any person who has had any form of potentially high-risk sexual activity will be deferred for a period of 6 months following the high-risk activity. A donor who has multiple sex partners will be regarded as being at potentially high risk regardless of sexual orientation. At no point does SANBS suggest that high-risk sexual practices are exclusive to the gay community, hence the self-exclusion questionnaire's comprehensive set of questions regarding various sexual activities and practices.

There are over 450 rules guiding donor selection with 
regard to medical conditions and lifestyle, and there are many groups of people whom we defer from donating, either temporarily or permanently. ${ }^{3}$ Some individuals in these groups may have a very low risk of blood-borne infections and their blood would probably be safe to give to patients, but since it is impossible to identify specific individuals at low risk it is safest to ask everyone in the higher risk groups not to donate blood.

The request not to donate blood can be disappointing and frustrating to some people who wish to do so. Our decisions are based on information and research about the effects our policies on blood supply safety, not out of a desire to discriminate against any particular group.

The aims of donor selection are to:

- select donors whose blood is most unlikely to transmit any infection

- collect enough blood to meet patients' needs

- make sure that donors themselves come to no harm through the blood donation process.

We have to balance these three aims while keeping the selection process clear and simple, bearing in mind that almost a million units of blood are collected each year - a mammoth task complicated by stringent quality control and logistics.

The preliminary findings of recent studies among MSM, such as the JEMS study conducted in Johannesburg and Durban and the Soweto Men's Study, have found their HIV prevalence to be more than double the Actuarial Scientists of South Africa (ASSA)'s estimate of a 15.5\% national HIV prevalence and the UNAIDS estimate of $18.1 \% .^{4-8}$

South Africa was one of the first countries in the world to lift the total ban on men who have sex with men donating blood. Other countries such as Sweden are only now starting to follow our example. We still have among the most progressive policies regarding MSM in the world, and while this may not be much consolation to gay men in stable relationships, it is testimony to SANBS's commitment to be as inclusive as possible with regard to the community we serve.

Internationally this is a very topical discussion. It is interesting to note that in the USA some politicians have called for the lifting of the ban against MSM donating blood and that this was countered by the Haemophiliac Society, a group whose members were severely affected by infected blood during the 1980s.

It is easy to get lost in all the numbers and emotions, but at SANBS we have the very tough responsibility of weighing up the right of an individual to donate blood against that of a patient to receive blood that is as safe as it is humanly possible to make it. The decision on which groups of the population will be or should be allowed to donate must be taken on the basis of scientific merit and the blood service's ability to implement policies that are clear and concise.

\section{Karin van den Berg \\ Zone Medical Officer, Eastern Cape \\ South African National Blood Service}

REFERENCES

1. The Editor. The Herald, Port Elizabeth, 6 January 2010.

2. South African National Blood Service. Comprehensive Donor Questionnaire. FRMDCD-016E Rev 1 (02-03-09).

3. South African National Blood Service. Guidelines for Medical Assessment of Blood Donors. 3rd ed. PM-MED-001 Rev 2 (01/10/2006).

4. Rispel L, Metcalf C. HIV prevalence and risk behaviour among men who have sex with men (MSM) in the Johannesburg/Ethekwini Men's Study (JEMS). 4th South African AIDS Conference, 31 March - 3 April 2009, Durban. Abstract 586.

5. Metcalf $C$, Rispel L. To what extent does the HIV epidemic among men who have sex with men (MSM) overlap with the generalised HIV epidemic in South Africa. Preliminary findings from the Johannesburg / Ethekwini Mens Study (JEMS). 4th South African AIDS Conference, 31 March - 3 April 2009, Durban. Abstract 597.

6. Lane T, Raymond H, Dladla S, et al. High HIV prevalence among MSM in Soweto: Results from the Soweto Men's Study. 4th South African AIDS Conference, 31 March - 3 April 2009, Durban. Abstract 597.

7. Actuarial Society of South Africa. ASSA2003 AIDS and demographics model. 2005. http://aids.actuarialsociety.org.za/ASSA2003-Model-3165.htm (accessed 13 May 2009)

8. UNAIDS. http://www.unaids.org/en/CountryResponses/Countries/south_africa. asp (accessed 13 May 2009).

\section{ERRATUM}

In 'Changes to the ART guidelines - an overview', which appeared on pp. 28 - 30 of the April 2010 issue of the Journal, the first sentence under the heading 'National regimens' and the heading to Table I should have read 'National regimens for adults and adolescents' and not 'National regimens for children and adolescents'. We apologise for these errors and have corrected them on the web version of the article, in which there are also other adjustments. 